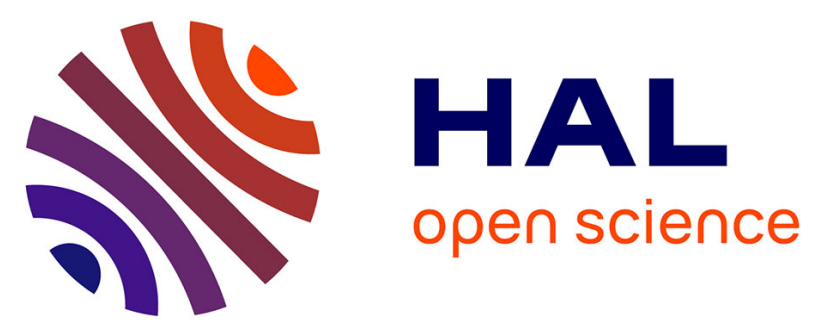

\title{
Biochemical and Monolayer characterization of Tunisian snake venom phospholipases
}

Douja Bairam, Imen Aissa, Hanen Louati, Houcemeddine Othman, Zaineb Abdelkafi-Koubaa, Najeh Krayem, Mohamed El Ayeb, Najet Srairi-Abid, Naziha Marrakchi, Youssef Gargouri

\section{To cite this version:}

Douja Bairam, Imen Aissa, Hanen Louati, Houcemeddine Othman, Zaineb Abdelkafi-Koubaa, et al.. Biochemical and Monolayer characterization of Tunisian snake venom phospholipases. International Journal of Biological Macromolecules, 2016, 89, pp.640-646. 10.1016/j.ijbiomac.2016.05.020 . pasteur-01405543

\section{HAL Id: pasteur-01405543 \\ https://hal-riip.archives-ouvertes.fr/pasteur-01405543}

Submitted on 30 Nov 2016

HAL is a multi-disciplinary open access archive for the deposit and dissemination of scientific research documents, whether they are published or not. The documents may come from teaching and research institutions in France or abroad, or from public or private research centers.
L'archive ouverte pluridisciplinaire HAL, est destinée au dépôt et à la diffusion de documents scientifiques de niveau recherche, publiés ou non, émanant des établissements d'enseignement et de recherche français ou étrangers, des laboratoires publics ou privés.

\section{(1)(1) $\$(0)$}

Distributed under a Creative Commons Attribution - NonCommercial - ShareAlikel 4.0 


\section{Accepted Manuscript}

Title: Biochemical and Monolayer characterization of Tunisian snake venom phospholipases

Author: Douja Baîram Imen Aissa Hanen Louati Houcemeddine Othman Zaineb Abdelkafi-Koubaa Najeh Krayem Mohamed El Ayeb Najet Srairi-Abid Naziha

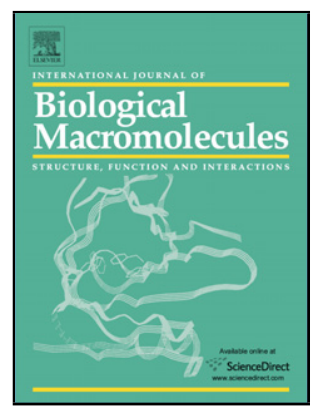
Marrakchi Youssef Gargouri

PII:

DOI:

Reference: S0141-8130(16)30431-7

BIOMAC 6081

To appear in: $\quad$ International Journal of Biological Macromolecules

Received date: $\quad 14-10-2015$

Revised date: $\quad 3-5-2016$

Accepted date: $\quad 4-5-2016$

Please cite this article as: Douja Bairam, Imen Aissa, Hanen Louati, Houcemeddine Othman, Zaineb Abdelkafi-Koubaa, Najeh Krayem, Mohamed El Ayeb, Najet Srairi-Abid, Naziha Marrakchi, Youssef Gargouri, Biochemical and Monolayer characterization of Tunisian snake venom phospholipases, International Journal of Biological Macromolecules http://dx.doi.org/10.1016/j.ijbiomac.2016.05.020

This is a PDF file of an unedited manuscript that has been accepted for publication. As a service to our customers we are providing this early version of the manuscript. The manuscript will undergo copyediting, typesetting, and review of the resulting proof before it is published in its final form. Please note that during the production process errors may be discovered which could affect the content, and all legal disclaimers that apply to the journal pertain. 


\section{Biochemical and Monolayer characterization of Tunisian snake venom phospholipases}

Douja Baîram ${ }^{1 \S}$, Imen Aissa ${ }^{2 \S}$, Hanen Louati ${ }^{2}$, Houcemeddine Othman ${ }^{1}$, Zaineb AbdelkafiKoubaa $^{1}$, Najeh Krayem ${ }^{2}$, Mohamed El Ayeb ${ }^{1}$, Najet Srairi-Abid ${ }^{1}$, Naziha Marrakchi ${ }^{1}$, Youssef Gargouri ${ }^{2}$ *

${ }^{1}$ Institut Pasteur de Tunis, Laboratoire des Venins et Biomolécules Thérapeutiques LR11IPT08, 13, place Pasteur, BP 74 ,1002 Tunis-Belvédère, Université de Tunis El Manar, Tunisie.

${ }^{2}$ Laboratoire de Biochimie et de Génie Enzymatique des Lipases, Ecole Nationale d'Ingénieurs de Sfax (ENIS). Route de Soukra, BP 1173, 3038 Sfax, Université de Sfax, Tunisie.

*Corresponding author: Prof. Youssef Gargouri, Laboratoire de Biochimie et de Génie Enzymatique des Lipases, ENIS, Université de Sfax, Route de Soukra, 1173 Sfax-Tunisie. Tel.: + 21674675055; Fax: + 21674675055

E-mail : ytgargouri@yahoo.fr

§These authors contribute equally in this work 


\begin{abstract}
The present study investigated the kinetic and interfacial properties of two secreted phospholipases isolated from Tunisian vipers'venoms: Cerastes cerastes (CC-PLA2) and Macrovipera lebetina transmediterranea (MVL-PLA2). Results show that these enzymes have great different abilities to bind and hydrolyse phospholipids. Using egg-yolk emulsions as substrate at $\mathrm{pH} 8$, we found that MVL-PLA2 has a specific activity of $1473 \mathrm{U} / \mathrm{mg}$ at $37^{\circ} \mathrm{C}$ in presence of $1 \mathrm{mM} \mathrm{CaCl}_{2}$. Furthermore the interfacial kinetic and binding data indicate that MVL-PLA2 has a preference to the zwitterionic phosphatidylcholine monolayers (PC). Conversely, CC-PLA2 was found to be able to hydrolyse preferentially negatively charged head group phospholipids (PG and PS) and exhibits a specific activity 9 times more important (13 $333 \mathrm{U} / \mathrm{mg}$ at $60^{\circ} \mathrm{C}$ in presence of $3 \mathrm{mM} \mathrm{CaCl}_{2}$ ). Molecular models of both CC-PLA2 and MVL-PLA2 3D structures have been built and their electrostatic potentials surfaces have been calculated. A marked anisotropy of the overall electrostatic charge distribution leads to a significantly difference in the dipole moment intensity between the two enzymes explaining the great differences in catalytic and binding properties, which seems to be governed by the electrostatic and hydrophobic forces operative at the surface of the two phospholipases.
\end{abstract}

Abbreviations: Phospholipids (PL), Secreted Phospholipase A2 (sPLA2), Cerastes cerastes venom Phospholipase A2 (CC-PLA2), Macrovipera lebetina transmediterranea (MVLPLA2), 1-2 dilauroyl-sn-glycero-3-Phosphatidylcholine (1,2 DLPC), 1-2dilauroyl-sn-glycero3-Phosphatidylethanolamine (1,2 DLPE), 1-2 dilauroyl-sn-glycero-3-Phosphatidylglycerol (1,2 DLPG), 1-2dilauroyl-sn-glycero-3-Phosphatidylserine (1,2 DLPS).

Keywords: Phospholipase A2, Biochemical characterization, Phospholipid monolayers.

\title{
1. INTRODUCTION
}

Snake venoms are complex mixtures of biological actives molecules [1], among them phospholipase A2 enzymes (EC 3.1.1.4) are the best-characterized components. Snake venoms phospholipases A2 are classified into two groups [2]. The secreted phospholipase A2 from Viperidae snake venoms fall under group II. They are generally $\mathrm{Ca}^{2+}$ dependant enzymes that catalyze the hydrolysis of the sn-2 fatty acid bond of phospholipids to release free fatty acids and lysophospholipids. These are small proteins (13-14 KDa), containing 120-125 
amino acid residues and 7 disulfide bridges. The amino acid sequences of over 280 snake venom PLA2 enzymes have been determined (A database of snake venom PLA2 enzymes is available at http://sdmc.lit.org.sg/Templar/DB/snaketoxin_PLA2/index.html). Their structural comparison indicates that they share 40-99\% identity in their amino acid sequences and hence significant similarity in their three dimensional folding [3]. They have a partially conserved structure that defines the PLA2 fold [4]. Despite this similarity, sPLA2 exhibit a wide variety of pharmacological properties such as anticoagulant, platelet aggregation inhibiting [5], bactericidal [6], anti-HIV [7], antimalarial and antiparasitic [8], antitumor [9] and antiangiogenic effects [10].

Generally there is a tendency to correlate pharmacological activities of a PLA2 enzyme to its phospholipid hydrolyzing ability. The in vitro studies can provide excellent information about the ability of the enzyme to hydrolyze specific phospholipids based on its head group specificity and/or fatty acyl group selectivity. It also helps determining the catalytic efficiency of the enzyme [4]. An interesting approach to study protein-lipid interactions is the use of lipid monolayers spread at the air/water interface [11]. It is a useful tool for comparing the relative surface activities of various proteins or in the case of a given protein its interactions with various lipid monolayers spread over an aqueous subphase of a given composition.

Two Tunisian Viperidae snakes are known and have been well studied: the first one is Macrovipera lebetina and the second one is Cerastes cerastes. Both of them contain non cytotoxic sPLA2. Macrovipera lebetina venom sPLA2 (MVL-PLA2) has a molecular mass of $13626.64 \pm 12$ Da with an isoelectric point of 4.69 [12].

Cerastes cerastes venom sPLA2 called CC-PLA2 is an acidic enzyme which has a molecular weight of $13737.52 \mathrm{Da}$ and reported to be the first glycosylated phospholipase A2 purified from snake venom with a rate of glycosylation of $2.5 \%$ [13]. The two enzymes showed antitumoral activities identified by their inhibition of adhesion and migration of tumoral cell lines. These pharmacological effects are dose dependent and do not depend on their enzymatic activities $[13,14]$. Thus, the authors showed that CC-PLA2 present a high enzymatic activity. However, to our knowledge, enzymatic activity of MVL-PLA2 was not reported. The aim of this work is to characterize CC-PLA2 and MVL-PLA2 with respect to their biochemical and interfacial properties in the same conditions. Moreover, for further comparison, 3-D structure models of the two enzymes are performed in an attempt to establish a structure-function relationship. 


\section{MATERIAL AND METHODS}

\subsection{Chemicals}

$\mathrm{NaCl}, \mathrm{CaCl}_{2}, \quad$ Tris- $\mathrm{HCl}$, Ethylene Diamine Tetra Acetic acid (EDTA), Sodium taurodeoxycholate (NaTDC), ethylene glycol tetra acetic acid (EGTA)were purchased from Sigma-Aldrich (St. Quentin-Fallavier, France). Chloroform supplied from SDS (Peypin, France) was used as spreading solvent.

\subsection{Phospholipids}

1-2dilauroyl-sn-glycero-3-Phosphatidylcholine (1,2 DLPC), 1-2 dilauroyl-sn-glycero-3Phosphatidylethanolamine (1,2 DLPE),1-2 dilauroyl-sn-glycero-3-Phosphatidylglycerol (1,2 DLPG), 1-2 dilauroyl-sn-glycero-3-Phosphatidylserine (1,2 DLPS) were purchased from Avanti Polar Lipids. All substrates are used without further purification.

\subsection{Phospholipases A2}

CC-PLA2 and MVL-PLA2 were purified from Two Tunisian Viperidae snakes: Cerastes cerastes and Macrovipera lebetina as described previously by Zouari-Kessentini et al. [13] and Bazaa et al. [12] respectively.

\subsection{Determination of protein concentration}

Protein concentration was measured spectrophotometrically according to the Bradford method [15], using BSA as a standard.

\subsection{Evaluation of the level of phospholipase activity}

Phospholipase activity was measured titrimetrically with a $\mathrm{pH}$-stat Metrohm (Switzerland), using egg-yolk emulsions as substrate in the presence of different concentrations of NaTDC $(0-10 \mathrm{mM})$ and $\mathrm{CaCl}_{2}(0-10 \mathrm{mM})$. With the $\mathrm{pH}$-stat method, phospholipase activity is measured on a mechanically stirred emulsion. Free fatty acids released with time are neutralized by adding titrated $\mathrm{NaOH}(0.1 \mathrm{~N})$ in order to maintain the $\mathrm{pH}$ at a constant end point value. $\mathrm{CC}$ PLA2 was used at a concentration of $0.3 \mathrm{mg} / \mathrm{ml}$ and MVL-PLA2 at a concentration of 0.86 $\mathrm{mg} / \mathrm{ml}$. One unit of phospholipase activity corresponds to $1 \mu$ mole of fatty acid liberated per minute under standard conditions. 


\subsection{Effect of temperature on phospholipases activities and stabilities}

The CC-PLA2 $(0.3 \mathrm{mg} / \mathrm{ml})$ and MVL-PLA2 $(0.86 \mathrm{mg} / \mathrm{ml})$ activities were determined at different temperatures $\left(25^{\circ} \mathrm{C}-60^{\circ} \mathrm{C}\right)$ at $\mathrm{pH}$ 8.5. The thermal stability was studied by incubating each enzyme at various temperatures $\left(25-90^{\circ} \mathrm{C}\right)$ for $30 \mathrm{~min}$ and measuring, after centrifugation, the residual activity under standard assay condition, using egg-yolk emulsion as substrate.

\subsection{Monomolecular film technique for kinetic measurements on SPLA2}

The monolayer study was performed as described previously by Pattus et al. [16]. Prior to each experiment, the Teflon trough used to form the monomolecular film was cleaned with water before being gently brushed with distilled ethanol and washed again with tap water. The aqueous subphase contained $10 \mathrm{mM}$ Tris- $\mathrm{HCl}, \mathrm{pH} 8,150 \mathrm{mM} \mathrm{NaCl}, 21 \mathrm{mM} \mathrm{CaCl}_{2}$, and 1 mM EDTA with all phospholipases tested. The buffer was prepared with double distilled water and filtered through a $0.22 \mu \mathrm{m}$ Millipore filter. Any residual surface-active impurities were removed before each assay by sweeping and suction of the surface. Kinetic experiments were performed at room temperature with a KSV-2200 barostat (KSV Helsinki) and a "zeroorder" Teflon trough equipped with a mobile Teflon barrier, which was used to compensate for the substrate molecules removed from the film by enzyme hydrolysis, thus maintaining the surface pressure constant. The latter was measured using a Wilhelmy plate (perimeter $3.94 \mathrm{~cm}$ ) attached to an electro-balance, which was connected in turn to a microprocessor controlling the movements of the mobile barrier. The subphase of the reaction compartment was continuously agitated with a $2-\mathrm{cm}$ magnetic stirrer moving at $250 \mathrm{rpm}$. The enzyme solution $(1-2 \mu \mathrm{L})$ was injected through the film over the stirrer with a Hamilton syringe. The surface area of the reaction compartment was $120 \mathrm{~cm}^{2}$ and its volume was $120 \mathrm{ml}$. The reservoir compartment was $148 \mathrm{~mm}$ wide and $249 \mathrm{~mm}$ long. Hydrolysis of phospholipid monolayers by sPLA2 results in the formation of lysophospholipid and free fatty acid. As these products are more water-soluble than the native phospholipid, they desorb from the monolayer, which results in a surface pressure decrease. Thus, phospholipase activity was monitored as change in surface pressure at constant total area. Activities were expressed as the number of moles of substrate hydrolysed by unit time and unit surface of the reaction compartment of the "zero-order" trough for appropriate sPLA2 concentration. All the experiments were carried out at $37^{\circ} \mathrm{C}$. 


\subsection{Molecular modeling of CC-PLA2 and MVL-PLA2}

Entries with accession numbers P0CAR9 and B5U6Z2 corresponding to CC-PLA2 and MVLPLA2, respectively were fetched from the UniProt database. The complete mature forms of the proteins were used for the modeling. The homology models of MVL-PLA2 and CC-PLA2 were obtained by submitting the sequences to the Phyre 2 server [17] using profile searching and Hidden Markov models to identify structural homologous of the protein target [18]. Models were refined in two stages of energy minimization using CHARMM molecular modelling package [19]. The best returned models were submitted to a quality assessment by establishing the Ramachandran Plot [20] and the ProSa profile [21].

The electrostatic potential of the two proteins was calculated using Adaptive Poisson Boltzmann Solver (APBS) program [19]. The PARSE force field parameters for partial atomic charges and radii were assigned to the protein residues. The protein dipole moment was also calculated using CHARMM.

\section{RESULTS}

\subsection{Biochemical and kinetic properties of the CC-PLA2 and MVL-PLA2}

\subsubsection{Effect of temperature on CC-PLA2 and MVL-PLA2 activities}

Phospholipase activities of the two enzymes were tested at temperatures ranging from 25 to $65^{\circ} \mathrm{C}$ using egg-yolk emulsion as substrate (Fig. 1). In contrast to MVL-PLA2 which displays its maximal activity at $37^{\circ} \mathrm{C}$ (Fig. 1A), CC-PLA2 is fully active at $60^{\circ} \mathrm{C}$. The specific activity of CC-PLA2 increased significantly (3.6-fold) when the temperature passed from 25 to $60^{\circ} \mathrm{C}$ (Fig. 1B). The optimum temperature for CC-PLA2 was higher than those of the thermoactive scorpion venoms PLA2 such as secreted phospholipases A2 purified from the venoms of Scorpio maurus and Heterometrus fulvipes which exhibit their maximum activities at $47^{\circ} \mathrm{C}$ and $50^{\circ} \mathrm{C}$, respectively [22,23]. (*Fig. 1 should be inserted in this section)

The thermostability of MVL-PLA2 and CC-PLA2 was also investigated by measuring the residual activity after $30 \mathrm{~min}$ of incubation at various temperatures. As shown in Fig. 2, MVL-PLA2 retained its full activity at temperatures ranging from 20 to $45^{\circ} \mathrm{C}$. This enzyme preserved about $71 \%$ and $45 \%$ of its maximal activity after incubation at $60^{\circ} \mathrm{C}$ and $90^{\circ} \mathrm{C}$, respectively. CC-PLA2 displays $100 \%$ of its maximal activity between $20^{\circ} \mathrm{C}$ and $50^{\circ} \mathrm{C}$.After incubation at $60^{\circ} \mathrm{C}$ and $90^{\circ} \mathrm{C}$, it conserved $93 \%$ and $54 \%$ respectively of its maximal activities. ${ }^{*}$ Fig. 2 should be inserted in this section) 


\subsection{2. $\mathrm{Ca}^{2+}$ dependence}

It is well established that $\mathrm{Ca}^{2+}$ is essential for both, activity and binding of phospholipases to their substrate [24]. In order to investigate the effect of $\mathrm{Ca}^{2+}$ on MVL-PLA2 and CC-PLA2 activities, we followed the egg-yolk emulsion hydrolysis by MVL-PLA2 and CC-PLA2 in presence of various $\mathrm{Ca}^{2+}$ concentrations. As shown in Fig.3, no phospholipase activity can be detected in the absence of $\mathrm{Ca}^{2+}$ for both phospholipases. The specific activity of purified MVL-PLA2 and CC-PLA2 reached $1473 \pm 39 \mathrm{U} / \mathrm{mg}$ in presence of $1 \mathrm{Mm} \mathrm{CaCl}_{2}$ (Fig. 3A) and $13333 \pm 247 \mathrm{U} / \mathrm{mg}$ in presence of $3 \mathrm{mM} \mathrm{CaCl}_{2}$ (Fig. $3 \mathrm{~B}$ ). ${ }^{\left({ }^{*} \mathrm{Fig} .\right.} 3$ should be inserted in this section)

\subsubsection{Bile salts inhibition of PLA2}

As shown in Fig. 4, NaTDC was not required to trigger MVL-PLA2 and CC-PLA2 activities. The maximum phospholipase activities were measured in the presence of 0 to $1 \mathrm{mM}$ NaTDC for MVL-PLA2 (Fig. 4A) and in presence of 0 to $3 \mathrm{mM} \mathrm{NaTDC}$ for CC-PLA2 (Fig. 4B). Above these concentrations the phospholipases activities decreased progressively. ${ }^{*}$ Fig. 4 should be inserted in this section)

\subsection{Variations with surface pressure in the catalytic activities of CC-PLA2 and MVL- PLA2}

MVL-PLA2 and CC-PLA2 were testes on hydrolysis of zwitterionic phospholipid DLPC, a partial negatively charged phospholipid DLPE as well as two negatively charged head group phospholipids DLPG and DLPS monolayers. Activity-surface pressure profiles are illustrated in Figure 5. It is clear that the affinities of the two enzymes towards the different phospholipid films are significantly different. In fact, MVL-PLA2 activities measured on DLPC and DLPE films are higher than those measured on DLPG and DLPS (Fig. 5A). The highest enzymatic activities were measured at $25 \mathrm{mN} . \mathrm{m}^{-1}$ with DLPC (1.02 mol cm$~^{-2} \min ^{-1} \mathrm{M}^{-1}$ ). Only $0.66 \mathrm{~mol} \mathrm{~cm}^{-2} \min ^{-1} \mathrm{M}^{-1}$ was measured with DLPE, at the same surface pressure. Using DLPG and DLPS films, the highest enzymatic activities measured are $0.21 \mathrm{~mol} \mathrm{~cm}^{-2} \min ^{-1} \mathrm{M}^{-1}$ and $0.07 \mathrm{~mol} \mathrm{~cm}^{-2} \min ^{-1} \mathrm{M}^{-1}$, respectively.

In contrast, the activity $v s$ surface pressure profiles of CC-PLA2 (Fig.5B) show clearly that this enzyme hydrolyses more efficiently negatively charged head group substrates especially DLPG $\left(1.66 \mathrm{~mol} \mathrm{~cm}^{-2} \mathrm{~min}^{-1} \mathrm{M}^{-1}\right)$ and to a lesser extent DLPS $\left(0.64 \mathrm{~mol} \mathrm{~cm}^{-2} \mathrm{~min}^{-1}\right.$ $\left.\mathrm{M}^{-1}\right)$ and the partial negatively head group DLPE $\left(0.32 \mathrm{~mol} \mathrm{~cm}^{-2} \min ^{-1} \mathrm{M}^{-1}\right)$ at a high surface pressure of $20 \mathrm{mN} \cdot \mathrm{m}^{-1}$. The lowest catalytic activity was measured with zwitterionic phospholipid DLPC films. These results are in agreement with the fact that 
phosphatidylglycerol is considered to be the best substrate for many known sPLA2 [25]. In a previous work, Singer et al. [26] showed that the hydrolysis reaction of mammalian sPLA2 on anionic vesicles of PG and PS started immediately after the addition of sPLA2 with no discernible lag, and the specific activities measured confirms that PG was the preferred substrate for SPLA2. ${ }^{*}$ Fig. 5 should be inserted in this section)

\subsection{Molecular modeling of CC-PLA2 and MVL-PLA2}

The model building of both MVL-PLA2 and CC-PLA2 uses the X-ray structure from Agkistrodonhalys Pallas phospholipase A2 (PDB code: 1JIA) as template. As shown in Fig.6, the alignment with the template using T-coffee method [27] is obtained at high confidence level (56.2\% with CC-PLA2 and 63.11\% with MVL-PLA2). Structural superimposing gave an RMSD value of 2.7 angstroms (Fig.7). Both proteins share the same fold consisting of three alpha helices, a calcium binding loop and a two-strand beta sheet. Helices $\mathrm{H}_{2}$ and $\mathrm{H}_{3}$ represent a structural support for the catalytic triad. Residues of the catalytic triad were identified by structural alignment with the template PLA2 and the available annotation data of the structure. These correspond to G45/H63/D104 and G45/H63/D105 (numbering according to the complete sequence in the Uniprot database) for CC-PLA2 and MVL-PLA2 respectively. In analogy to similar systems [25, 28] $\mathrm{H}_{1}$ helix (residues 18-29) is in the forefront of the interaction interface with the lipid membrane head groups prior to the surface activation. In each PLA2, two residues: (L18/Y19 in CC-PLA2 and L18/T19 in MVL-PLA2) are mainly involved in anchoring the protein to the lipid interface. ${ }^{\left({ }^{*} \text { Fig. } 6 \text { should be inserted in this section) }\right.}$ Interestingly, the repartition of the surface charges of both proteins is quite different. Positive charges are heavily concentrated nearby the $\mathrm{H}_{1}$ helix in CC-PLA2 which might contain key residues for the interaction with the negatively charged lipid membrane molecules. The dipole moment resulting from its charge distribution anisotropy is visualized by an arrow on Fig.7. It is directed from the center of the molecule and oriented from the lowest to the highest positive charge density. The size of the arrow is proportional to the intensity of the anisotropy (Fig.7). The amplitude of dipole moment for CC-PLA2 is of $470 \mathrm{D}$ whereas that of MVL-PLA2 is of 97 D. The dipole moments of CC-PLA2 and MVL-PLA2 point toward the helix $\mathrm{H}_{1}$ and the surface patch made by the C-termini loop, respectively. ( ${ }^{*}$ Fig. 7 should be inserted in this section) 


\section{DISCUSSION}

Despite similarity in their structures, phospholipases A2 exhibit a wide spectrum of pharmacological activities and catalytic properties. As shown in Fig.6, BthA-I, vipoxin, myotoxin II, CC-PLA2 and MVL-PLA2 have higher than $40 \%$ of similarity while they have different pharmacological activities. In Fact, CC-PLA2 and MVL-PLA2 have anti-tumoral activities [10], BthA-I has a hypotensive response in rats [29], Vipoxin has been found to possess hemolytic activity [30] and Myotoxin II induce myotoxic effects [31]. The activities of BthA-I, vipoxin and myotoxinII are not related to their catalytic activities [29-31]. In this work, we report for the first time, the biochemical and interfacial kinetic characteristics of the two Asp49 phospholipases A2 isolated from Tunisian vipers: CC-PLA2 from Cerastes cerastes [13], and MVL-PLA2 from Macrovipera lebetinatrans mediterranea [14].

Zouari-Kessentini et al. [13] have reported that CC-PLA2 was characterized by presenting an enzymatic activity of $1800 \mathrm{U} / \mathrm{mg}$ at $\mathrm{pH} 7$ using phosphatidylcholine as substrate, while enzymatic activity of MVL-PLA2 was not yet determined. Interestingly, after the optimization of reaction conditions, we found that CC-PLA2 presents a specific activity of $13333 \pm 247 \mathrm{U} / \mathrm{mg}$ at $60^{\circ} \mathrm{C}$ and $\mathrm{pH} 8$, while MVL-PLA2 presents a specific activity of $1473 \pm$ $39 \mathrm{U} / \mathrm{mg}$ at $37^{\circ} \mathrm{C}$ and $\mathrm{pH} 8$ against the same substrate. As it can be seen, the optimal activity of CC-PLA2 is approximately 9 fold higher than that of MVL-PLA2. These findings place CC-PLA2 within the thermoactive enzymes class. Thus, in our knowledge, this CC-PLA2 is the first enzyme from snake venom able to act at $60^{\circ} \mathrm{C}$. Phospholipase A2 from the snakes Crotalus durissus terrificus, Bothriechis lateralis, Crotalus durissu sruruima exhibits their activities at $18^{\circ} \mathrm{C}, 30^{\circ} \mathrm{C}$ and $40^{\circ} \mathrm{C}$, respectively [32,33,34]. In contrast, MVL-PLA2 behavior is comparable to many mammalian pancreatic PLA2 [35] and some snake venoms PLA2 such as Hydrophis cyanocinctus and Bothriopsis bilineata PLA2 [36, 37].

Although the high sequences similarity, biochemical and kinetic properties of the two PLA2 are significantly different. The difference in hydrolysis rates can be correlated to a difference in interfacial binding to phospholipid. Thus, the hydrolytic activity of secretory phospholipase A2 (PLA2) is influenced by the chemical nature of phospholipid molecules and their physical state. In order to achieve strong binding of PLA2 on its substrates, many previous works have used anionic lipid dispersion to characterize the orientation and penetration of PLA2 on membrane surfaces [38,22]. The monolayer technique offers an attractive possibility to test the phospholipase ability to interact with various phospholipids. In 
this study, monolayer technique was used at $37^{\circ} \mathrm{C}$ to measure the activities of CC-PLA2 and MVL-PLA2 on zwitterionic and negatively charged head groups'phospholipid films.

As we can see on figure 3, both PLA2 are able to hydrolyse various phospholipid films between 5 to $30 \mathrm{mN} / \mathrm{m}$. CC-PLA2 was more active on negatively charged head group DLPG and DLPC than the partial negatively charged phospholipid DLPE and the zwitterionic substrate DLPC. The behaviour of this enzyme is similar to those of the most sPLA2s well known by their higher activity on anionic phospholipids such as phosphatidylglycerol (PG), phosphatidylethanolamine (PE), and phosphatidylserine (PS) [39]. Verheij et al. [40] reported that Vipera Berus phospholipase hydrolyses efficiently phosphatidylcholine only at medium surface pressure. At high surface pressures a decrease in hydrolysis rate was observed. When the zwitterionic phosphatidylcholine film is replaced by a negatively charged phospholipid monolayer, the enzyme can penetrate and hydrolyse the monolayer even at higher pressure. Moreover, the apparent binding constants of Akgistrodon piscivorus piscivorus venom PLA2 to phospholipids range over a factor of about 200 from zwitterionic phosphatidylcholine to negatively charged head phosphatidylglycerol [41]. On the other hand, MVL-PLA2 showed a preference to phosphatidylcholine films comparable to the particular Group-IA (GIA) and group-XIV (GXIV) of sPLAs which are more active against zwitterionic phosphatidylcholine (PC) vesicles [39]. It is expected that the concentration of calcium required for maximal sPLA2 activity will depend on the fraction of enzyme bound to the membrane and the affinity of the enzyme active site for the phospholipid substrate. This synergism presumably explains why MVL-PLA2 requires 3 fold lesser concentration of calcium than CC-PLA2 to hydrolyze egg-yolk phospholipids emulsion which contains $60 \%$ of PC.

In general, the penetrating power of the phospholipase is correlated to the pharmacological properties of the enzyme. It is well established that some venoms sPLA2, which are very toxic, are able to hydrolyse phospholipid monolayers at high surface pressure $\left(20-40 \mathrm{mNm}^{-1}\right)$. This kinetic property was correlated to the efficient attack of biological membranes. For example, anticoagulant phospholipases hydrolyse highly packed monomolecular films of phospholipids without any lag time while non-anticoagulant phospholipases present a low penetrating power [40]. Saikia et al. [42] confirmed the correlation between catalytic and erythrocytes membrane damaging activities of an acidic PLA2 purified from Daboia russelli venom. Moreover, venom glands Scorpio maurus PLA2 [22] and marine snail digestive PLA2 [43] were found to exhibit hemolytic activity towards erythrocytes which could be related to their ability to interact with phospholipids'monolayer at high surface pressure. In our case, MVL-PLA2 and CC-PLA2 are known to be non toxic 
enzymes [10] while they could interact efficiently with surface phospholipids at high surface pressure. Further structural analysis and site directed mutagenesis could highlight our knowledge about this contradiction between the high penetrating power and hydrolysis activity to the non toxicity of the two enzymes.

Electrostatic effects have long been considered crucial to interfacial recognition by sPLA2. The preference of many PLA2s for anionic surfaces, and the negative effect of salt addition to the reaction solution helped to verify this hypothesis [44]. Thus, the electrostatic potential surfaces of CC-PLA2 and MVL-PLA2 3D structure models were analysed to tempt to explain their differences in phospholipids hydrolysis capacities. Although CC-PLA2 and MVL-PLA2 have similar global charges (Table 1), their electrostatic potential maps are significantly different due to charge distribution on the surface. A marked anisotropy of electrostatic charge distribution giving rise a dipole moment which was found to be 5 fold more intense for CC-PLA2 (470 D), as compared to that of MVL-PLA2 (97 D) (Fig.7). Dipole moment and electrostatic potential calculations suggest that the interaction interface with the lipid membrane might favor the binding of anionic substrates types for CC-PLA2 while the zwitterionic lipids are more favored for MVL-PLA2 since the polarity of the enzyme decreases and the positive charges at the surface are delocalized from the lipidinteracting interface. In fact, the contribution of electrostatic properties of PLA2 interface was previously suggested to be determinant for the enzyme selectivity and in the control of the apparent rate of the lipids hydrolysis [28]. Here we showed for the first time the dipole moment sPLA2 isolated from the snake venoms, which can also explain the high penetrating power of CC-PLA2. Indeed, a correlation between the intensity of dipole moment and activities of other molecules have been reported explicitly in the work of Alakoskela et al. [45] while studying the penetrating capacity of pregnanolone with several monolayers. This phenomena result from a dipole-dipole interaction between the protein and the lipid layer constituting molecules. The protein and the membrane might align their dipole moments in a way to be able to orient charges of opposite signs allowing the system to decrease the electrostatic repulsion, thus imposing a specific orientation that could favor the membrane penetration. At this level, the high intensity of dipole moment of PLA2 could boost the displacement of the protein through the membrane.

\section{Conclusion}

Although their similarity, we have revealed in this study a significant differences between the two tunisian Viperidae snake venoms PLA2: Macrovipera lebetina (MVL-PLA2) and 
Cerastes cerastes (CC-PLA2). The main conclusions from our experimental data indicate that CC-PLA2 is a thermoactive enzyme which exhibits a higher activity than MVL-PLA2 and showed a preference to a negatively charged head group phospholipids. These characteristics seem to be related to an interesting dipole moment created by a marked anisotropy of electrostatic charge which was determinant for the enzymes selectivity and activity. Nevertheless, further experiments are needed to correlate these characteristics to the pharmacological properties of the enzymes.

\section{Acknowledgements}

We are grateful to Ms Nadia Chermiti for his help during the monolayer study. This work received financial support from the Ministry of Higher Education, Scientific Research in Tunisia.

\section{References}

[1] D.C. Koh, A. Armugam, K. Jeyaseelan, Snake venom components and their applications in biomedicine, Cell. Mol. Life Sci. 63 (2006) 3030-3041

[2] D. A. Six, E. A. Dennis, The expanding superfamily of phospholipase A2 enzymes: Classification and characterization, Biochim Biophys Acta.1488 (2000) 1-19.

[3] D. L. Scott, Phospholipase A2: structure and catalytic properties. In: Venom Phospholipase A2 Enzymes: Structure, Function and Mechanism, Kini R. M., ed. Wiley, Chichester, 1997, pp. 97-128.

[4] R. M. Kini, Excitement ahead: structure, function and mechanism of snake venom phospholipase A2 enzymes, Toxicon 42 (2003) 827-840.

[5] V. L. Karbovskiy, O. M. Savchuk, G. L. Volkov, N. V. Zaichko, T. Buchan, Influence of proteins from the Agkistrodon blomhoffii ussuriensis snake venom on platelets, Ukrain'skyi Biokhimichnyi Zhurnal 79 (2007) 82-89.

[6] A. Karray, Y.B. Ali, Y. Gargouri, S. Bezzine, Antibacterial properties of chicken intestinal phospholipase A2, Lipids Health Dis 104 (2011).

[7] D. Fenard, G. Lambeau, E. Valentin, J. C. Lefebvre, M. Lazdunski, A. Doglio, Secreted phospholipases A2, a new class of HIV inhibitors that block virus entry into host cells, J. Clin. Invest. 104 (1999) 611-618. 
[8] C. Deregnaucourt, J. Schrével, Bee venom phospholipase A2 induces stage-specific growth arrest of the intraerythrocytic Plasmodium falciparum via modifications of human serum components,” J. Biol. Chem. 275 (2000) 39973-39980.

[9] S. Sarray, J. Luis, M. El Ayeb, N. Marrakchi. Snake Venom Peptides: Promising Molecules with Anti-Tumor Effects. Bioactive Food Peptides in Health and Disease, Chapter 9, (2013) pp: 219-238.

[10] R. Zouari-Kessentini, N. Srairi-Abid, A. Bazaa,M. El Ayeb, J. Luis, N. Marrakchi. Antitumoral Potential of Tunisian Snake Venoms Secreted Phospholipases A2. BioMed Res. Int. (2013) 1-9.

[11] R. Maget-Dana, The monolayer technique: a potent tool for studying the interfacial properties of antimicrobial and membrane-lytic peptides and their interactions with lipid membranes, Biochim. Biophys. Acta 1462 (1999) 109-140.

[12] A. Bazaa, N. Marrakchi, M. El Ayeb, L. Sanz, J.J. Calvete, Snake venomics: comparative analysis of the venom proteomes of the Tunisian snakes Cerastes cerastes, Cerastes vipera and Macrovipera lebetina, Proteomics 5 (2005) 4223-4235.

[13] R. Zouari-Kessentini, J. Luis, A. Karray, O. Kallech-Ziri, N. Srairi-Abid, A. Bazaa, E. Loret, S. Bezzine, M. El Ayeb, N. Marrakchi ,Two purified and characterized phospholipases A2 from Cerastes cerastes venom, that inhibit cancerous cell adhesion and migration, Toxicon 53 (2009) 444-453.

[14] A. Bazaa, E. Pasquier, C. Defilles, I. Limam, R. Kessentini-Zouari, O. Kallech-Ziri, A. El Battari, D. Braguer, M. El Ayeb, N. Marrakchi, J. Luis, MVL-PLA2, a snake venom phospholipase A2, inhibits angiogenesis through an increase in microtubule dynamics and disorganization of focal adhesions, PLoS One 5 (2010) e10124.

[15] M. M. Bradford, A Rapid and Sensitive Method for the Quantitation of Microgram Quantities of Protein Utilizing the Principle of Protein-Dye Binding, Anal. Biochem. 72 (1976) 248-254.

[16] F. Pattus, A.J. Slotboom, G.H. de Haas, Regulation of phospholipase A2 activity by the lipid-water interface: a monolayer approach, Biochemistry 13 (1979) 2691-2697. 
[17] L. A. Kelley, M. J. E. Sternberg, Protein structure prediction on the Web: a case study using the Phyre server, Nat. Protoc. 4 (2009) 363-371.

[18] R.M. Bennett-Lovsey, A.D. Herbert, M.J.E. Sternberg, L.A. Kelley, Exploring the extremes of sequence/structure space with ensemble fold recognition in the program Phyre, Proteins 70 (2008) 611-625.

[19] B.R. Brooks, C.L. Brooks, A.D. Mackerell Jr., L. Nilsson, R.J. Petrella, B.Roux, Y. Won, G.Archontis, C. Bartels, S. Boresch, A. Caflisch, L. Caves, Q. Cui, A.R. Dinner, M. Feig, S. Fischer, J. Gao, M. Hodoscek, W. Im, K. Kuczera, T. Lazaridis, J.Ma, V. Ovchinnikov, E. Paci, R.W.Pastor, C.B. Post, J.Z. Pu, M. Schaefer, B.Tidor, R.M. Venable, H.L. Woodcock, X.Wu, W.Yang, D.M. York, M. Karplus, CHARMM: the biomolecular simulation program. J. Comput. Chem. 30 (2009) 1545-1614.

[20] S.C. Lovell, I.W. Davis, W.B. Arendall III, P.I.W. de Bakker, J.M. Word, M.G. Prisant, J.S. Richardson and D.C. Richardson Structure validation by Calpha geometry: phi,psi and Cbeta deviation. Proteins: Structure, Function \& Genetics. 50 (2002) 437-450.

[21] M. Wiederstein, M.J. Sippl, ProSA-web: interactive web service for the recognition of errors in three-dimensional structures of proteins, Nucleic Acids Res. 35 (2007) W407-W410.

[22] H. Louati, N. Krayem, A. Fendri , I. Aissa, M.Sellami, S.Bezzine, Y.Gargouri, A thermoactive secreted phospholipase A2 purified from the venom glands of Scorpio maurus: relation between the kinetic properties and the hemolytic activity,Toxicon, 72 (2013) 133142.

[23] M. Ramanaiah, P.R. Parthasarathy, B. Venkaiah, Purification and properties of phospholipase A2 from the venom of scorpion, (Heterometrus fulvipes). Biochem. Int. 20 (1990) 931-940.

[24] D.L. Scott, P.B. Sigler, Structure and catalytic mechanism of secretory phospholipases A2. Adv. Protein Chem. 45 (1994) 53-88.

[25] J. M. Winget, Y. H. Pan, B. J. Bahnson, The interfacial binding surface of phospholipase A2s, Biochim Biophys Acta 1761 (2006) 1260-1269.

[26] A. Singer, F. Ghomashchi, C. Le Calvez, J. Bollinger, S. Bezzine, M. Rouault, M. Sadilek, E. Nguyen, M. Lazdunski, G. Lambeau, M. Gelb, Interfacial kinetic and binding 
properties of the complete set of human and mouse groups I, II, V, X, and XII secreted phospholipases A2, J. Biol. Chem. 277 (2002) 48535-48549.

[27] O. O'Sullivan, K. Suhre, C. Abergel, D.G. Higgins, C. Notredame, 3DCoffee: combining protein sequences and structures within multiple sequence alignments, J Mol Biol. 340 (2004) 385-395.

[28] S. Wee, D. Wiederschain, S.M. Maira, A. Loo, C. Miller, R. de Beaumont, F. Stegmeier, Y.M. Yao, Lengauer C, PTEN-deficient cancers depend on PIK3CB, Proc.Natl.Acad.Sci. 105 (2008) 13057-13062.

[29] S.H. Andrião-Escarso, A.M. Soares, M.R.M. Fontes, A.L. Fuly, F.M.A. Corrêa, J.C. Rosa, L.J. Greene, J.R. Giglio, Structural and functional characterization of an acidic platelet aggregation inhibitor and hypotensive phospholipase A2 from Bothrops jararacussu snake venom. Biochem. Pharmacol. 64 (2002) 723-732.

[30] S. Stoykova, Y. Goranova, I. Pantcheva, V. Atanasov, D. Danchev, S. Petrova, Hemolytic activity and platelet aggregation inhibitory effect of vipoxin's basic sPLA2 subunit, Interdiscip Toxicol. 6 (2013) 136-140.

[31] R.K. Arni, M.R.M. Fontes, C. Barberato, J.M. Gutiérrez, C. Diaz, R.J. Ward, Crystal Structure of Myotoxin II, a Monomeric Lys49- Phospholipase A2 Homologue Isolated from the Venom of Cerrophidion (Bothrops) godmani. Archives of Biochemistry and Biophysics 366 (1999) 177-182

[32] M. H. Toyama, D. G. de Oliveira, L. O.S. Beriam, J.C. Novello, L. Rodrigues-Simioni, S.Marangoni, Structural, enzymatic and biological properties of new PLA2 isoform from Crotalus durissus terrificus venom, Toxicon 41 (2003) 1033-1038.

[33] M. Van der Laat, J. Fernández,, J. Durban, E. Villalobos, E. Camacho, J. J. Calvete, B. Lomonte, Amino acid sequence and biological characterization of BlatPLA2, a non-toxic acidic phospholipase A2 from the venom of the arboreal snake Bothriechis lateralis from Costa Rica, Toxicon 73 (2013) 71-80

[34] E.B.S. Diz Filho, S. Marangoni, D.O. Toyama, F.H.R. Fagundes, S.C.B. Oliveira, F.V. Fonseca, A.K. Calgarotto, P.P. Joazeiro, M.H. Toyama, Enzymatic and structural 
characterization of newPLA2 isoform isolated from white venom of Crotalus durissus ruruima, Toxicon 53 (2009) 104-114.

[35] A. Karray, F. Frikha, A. Ben Bacha, Y. Ben Ali, Y. Gargouri, S. Bezzine, Biochemical and molecular characterization of purified chicken pancreatic phospholipase A2, Febs J. 276 (2009) 4545-4554.

[36] S.A. Ali, J.M. Alam, S. Stoeva, J. Schütz, A. Abbasi, Z.H. Zaidi, W. Voelter, Sea snake Hydrophis cyanocinctus venom. I. Purification, characterization and N-terminal sequence of two phospholipases A2, Toxicon 37 (1999) 1505-1520.

[37] V. C. Carregari, R.S.Floriano, L.Rodrigues-Simioni, F. V. Winck, P. A. Baldasso, L. A. Ponce-Soto, S. Marangoni, Biochemical, Pharmacological, and Structural Characterization of New Basic PLA2 Bbil-TX from Bothriopsis bilineata Snake Venom, BioMed Res. Int. (2013) pp.12.

[38] A. Karray, Z. Zarai, Y. Gargouri, R. Verger, S. Bezzine, Kinetic properties of pancreatic and intestinal sPLA2 from chicken and mammals using the monomolecular film technique, $\mathrm{J}$ Colloid Interface Sci. 15 (2011) 620-625.

[39] E.A. Dennis, J. Cao, Y.-H. Hsu, V. Magrioti, G. Kokotos, Phospholipase A2 enzymes: physical structure, biological function, disease implication, chemical inhibition, and therapeutic intervention, Chem. Rev. 111 (2011) 6130-6185.

[40] H. M. Verheij, M-C Boffa, C. Rothen, M-C Bryckaert, R. Verger, G. H. de Haas, Correlation of Enzymatic Activity and Anticoagulant Properties of Phospholipase A2, Eur. J. Biochem. 112 (1980) 25-32.

[41] M. E. Gadd, R. L. Biltonen, Characterization of the Interaction of Phospholipase A2 with Phosphatidylcholine-Phosphatidylglycerol Mixed Lipids, Biochemistry 39 (2000) 9623-9631.

[42] D. Saikia, N. K. Bordoloi , P. Chattopadhyay, S. C S. S. Ghosh , A. K. Mukherjee, Differential mode of attack on membrane phospholipids by an acidic phospholipase A2 (RVVA-PLA2-I) from Daboia russelli venom, Biochim. Biophys. Acta 1818 (2012) 31493157. 
[43] Z. Zarai, A. Ben Bacha, H. Horchani, S. Bezzine, N. Zouari, Y. Gargouri,H. Mejdoub, A novel hepatopancreatic phospholipase A2 from Hexaplex trunculus with digestive and toxic activities. Arch. Biochem. Biophys. 494 (2010) 121-129.

[44] O.G. Berg, J. Rogers, B.-Z. Yu, J. Yoa, L.S. Romsted, M.K Jain, Thermodynamic and kinetic basis of interfacial activation: resolution of binding and allosteric effects on pancreatic phospholipase A2 at zwitterionic interfaces, Biochemistry 36 (1997) 14512-14530.

[45] J-M.I. Alakoskela, T. Soderlund, J. M. Holopainen, P. K. J. Kinnunen, Dipole Potential and Head-Group Spacing Are Determinants for the Membrane Partitioning of Pregnanolone, Mol. Pharmacol. 66 (2004) 161-168.

\section{Figure captions}

Fig.1. Effects of temperature on MVL-PLA2 (white diamond) and CC-PLA2 (black diamond) activities. The enzyme activity was tested at various temperatures using egg-yolk emulsion as substrate in the presence of $2 \mathrm{mM} \mathrm{CaCl}_{2}$ and $2 \mathrm{mM} \mathrm{NaTDC}$ at $\mathrm{pH}$ 8.5.

Fig.2. Effects of temperature on MVL-PLA2 (white diamond) and CC-PLA2 (black diamond) stability. The enzyme stability was tested using egg-yolk emulsion as substrate in the presence of $2 \mathrm{mM} \mathrm{CaCl}_{2}$ and $2 \mathrm{mM} \mathrm{NaTDC}$ at $\mathrm{pH} 8.5$ after incubation $30 \mathrm{~min}$ at different temperatures.

Fig. 3. Effect of $\mathrm{CaCl}_{2}$ concentration on MVL-PLA2 (white diamond) and CC-PLA2 (black diamond) activities. Enzyme activity was measured at various concentrations of $\mathrm{CaCl}_{2}$ using egg-yolk emulsion as substrate at $\mathrm{pH} 8.5$ in the presence of $2 \mathrm{mM} \mathrm{NaTDC}$ at $37^{\circ} \mathrm{C}$ for MVLPLA2 and $60{ }^{\circ} \mathrm{C}$ for MVL-PLA2. The star indicates the of phospholipase activity measured in absence of $\mathrm{CaCl}_{2}$ and in the presence of $10 \mathrm{mM}$ EGTA.

Fig.4. Effect of increasing concentration of NaTDC on MVL-PLA2 (white diamond) and CCPLA2 (black diamond) activities. Phospholipase activity was measured using egg-Yolk emulsion as substrate at $\mathrm{pH} 8.5$ and at $37^{\circ} \mathrm{C}$ in the presence of $1 \mathrm{mM} \mathrm{CaCl}_{2}$ for MVL-PLA2 and at $\mathrm{pH} 8.5$ and at $60^{\circ} \mathrm{C}$ in the presence of $3 \mathrm{mM} \mathrm{CaCl}_{2}$ for CC-PLA2. 
Fig.5. Variation of MVL-PLA2 (A) and CC-PLA2 (B) activities with surface pressure measured on 1,2 $\mathrm{DiC}_{12}$-PC (black diamond), 1,2 $\mathrm{DiC}_{12}-\mathrm{PE}$ (white diamond), 1,2 $\mathrm{DiC}_{12}-\mathrm{PG}$ (black circle) and 1,2 $\mathrm{DiC}_{12}$-PS (white circle). Each enzyme was injected under the substrate into the reaction compartment of a zero order trough (volume, $130 \mathrm{ml}$; surface area, 108.5 cm2). Buffer: $10 \mathrm{mM}$ Tris- $\mathrm{HCl}, \mathrm{pH} 8,150 \mathrm{mM} \mathrm{NaCl}, 21 \mathrm{mM} \mathrm{CaCl}$, and 1mM EDTA Activities are expressed as the number of moles of substrate hydrolysed per time unit (min) and surface unit $(\mathrm{cm} 2)$ at $37^{\circ} \mathrm{C}$ and at the appropriate phospholipases concentrations.

Fig.6. Multiple alignment of CC-PLA2, MVL-PLA2, bAhp (PDB code: 1JIA), Vipoxin(PDB code 1AOK), Myotoxin (PDB code 1GOD) and BthA-I (PDB code 1ZL7) sequences effected with T-coffee method. The blue shading represents the conservation level at each column of the alignment. Dark blue represents the most conserved positions. Residues of the catalytic dyad are marked in the red box.

Fig.7. Surface representations of MVL-PLA2 and CC-PLA2. The potential surfaces binding to various substrates are represented by Van der Waals's colored code where red and blue represent the net negative and positive charges, respectively. White colour represents the total neutral positions. The electrostatic potential of the two proteins was calculated using Adaptive Poisson Boltzmann Solver (APBS) program. The protein dipole moment represented by an arrow was determined using CHARMM. 
Fig. 1.

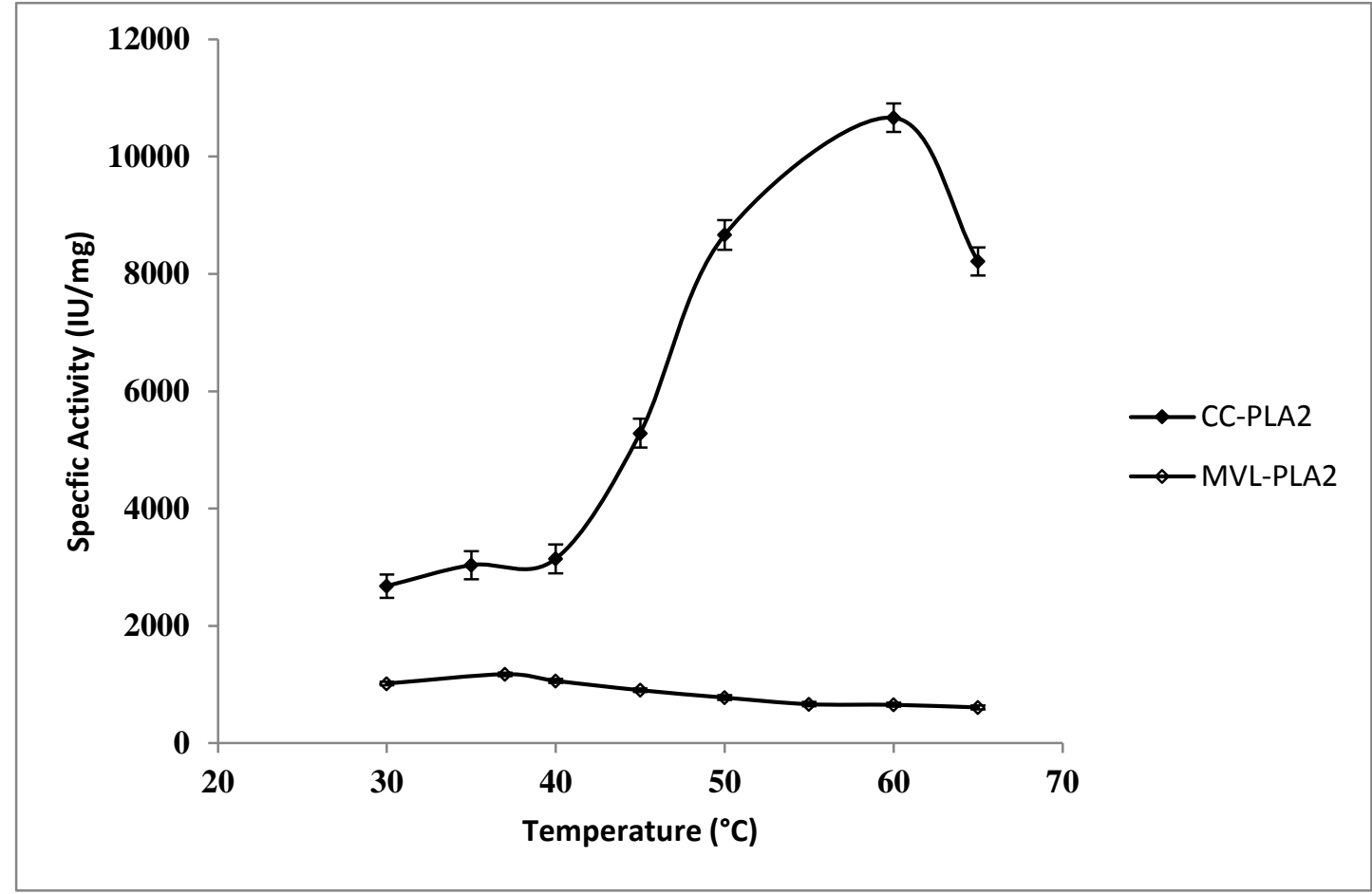

Fig. 2.

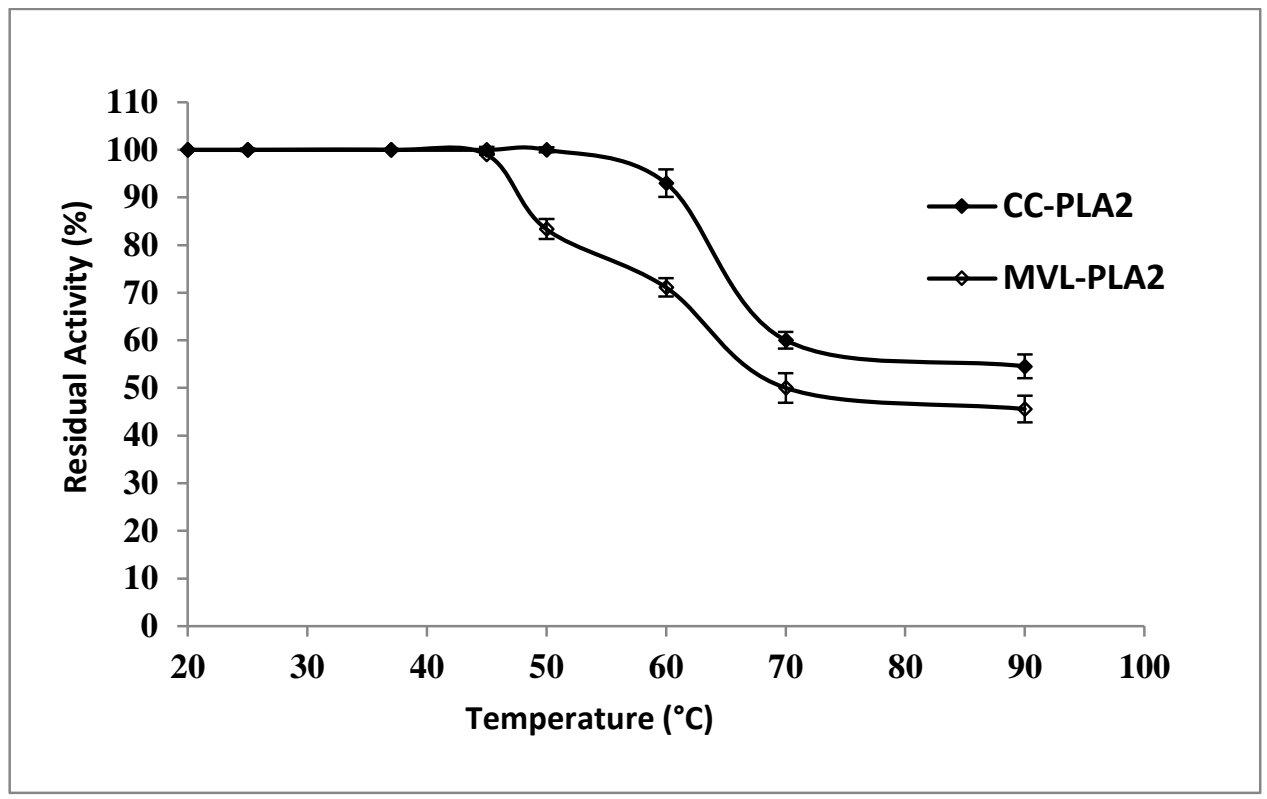


Fig. 3.

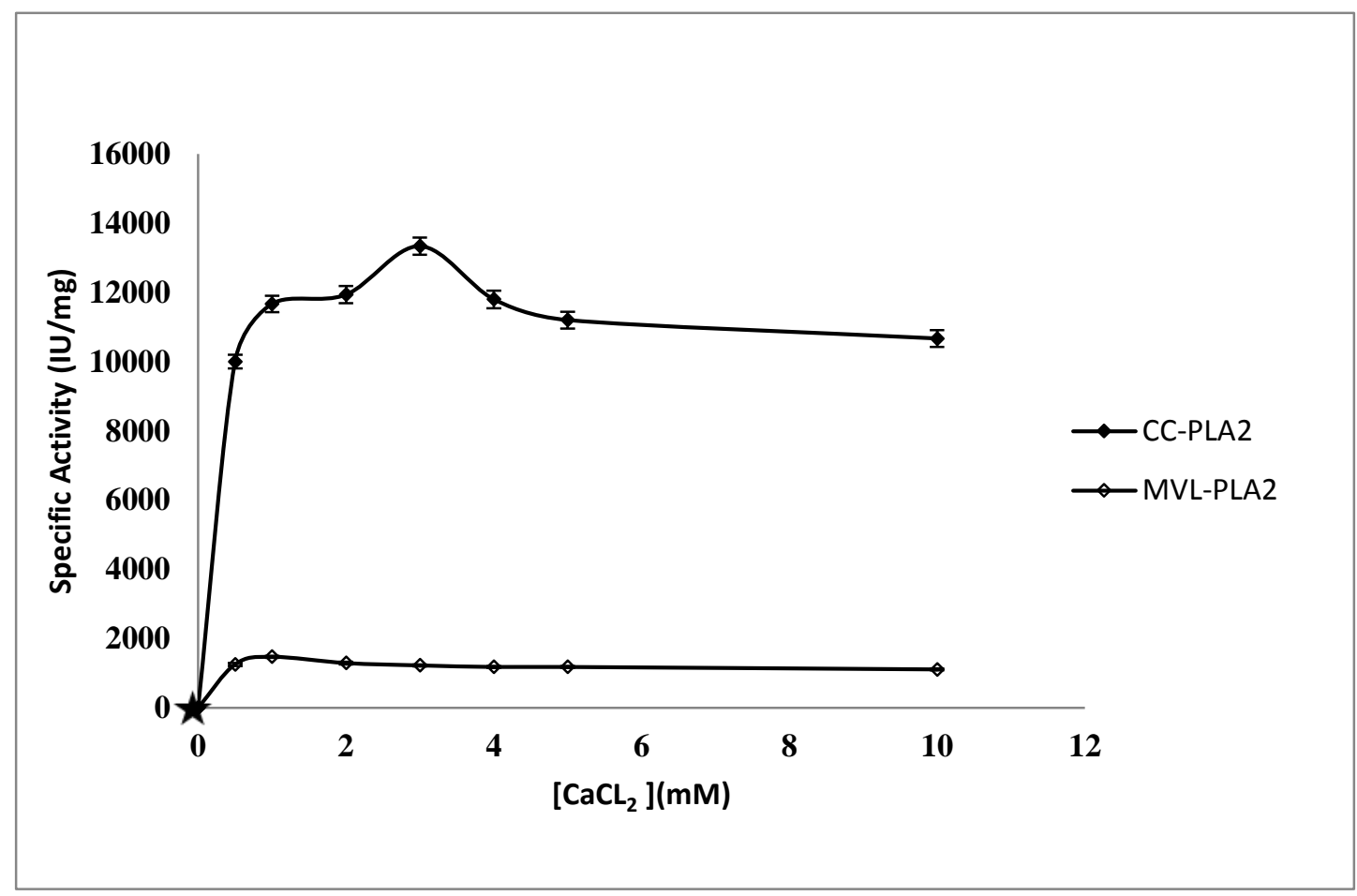

Fig. 4.

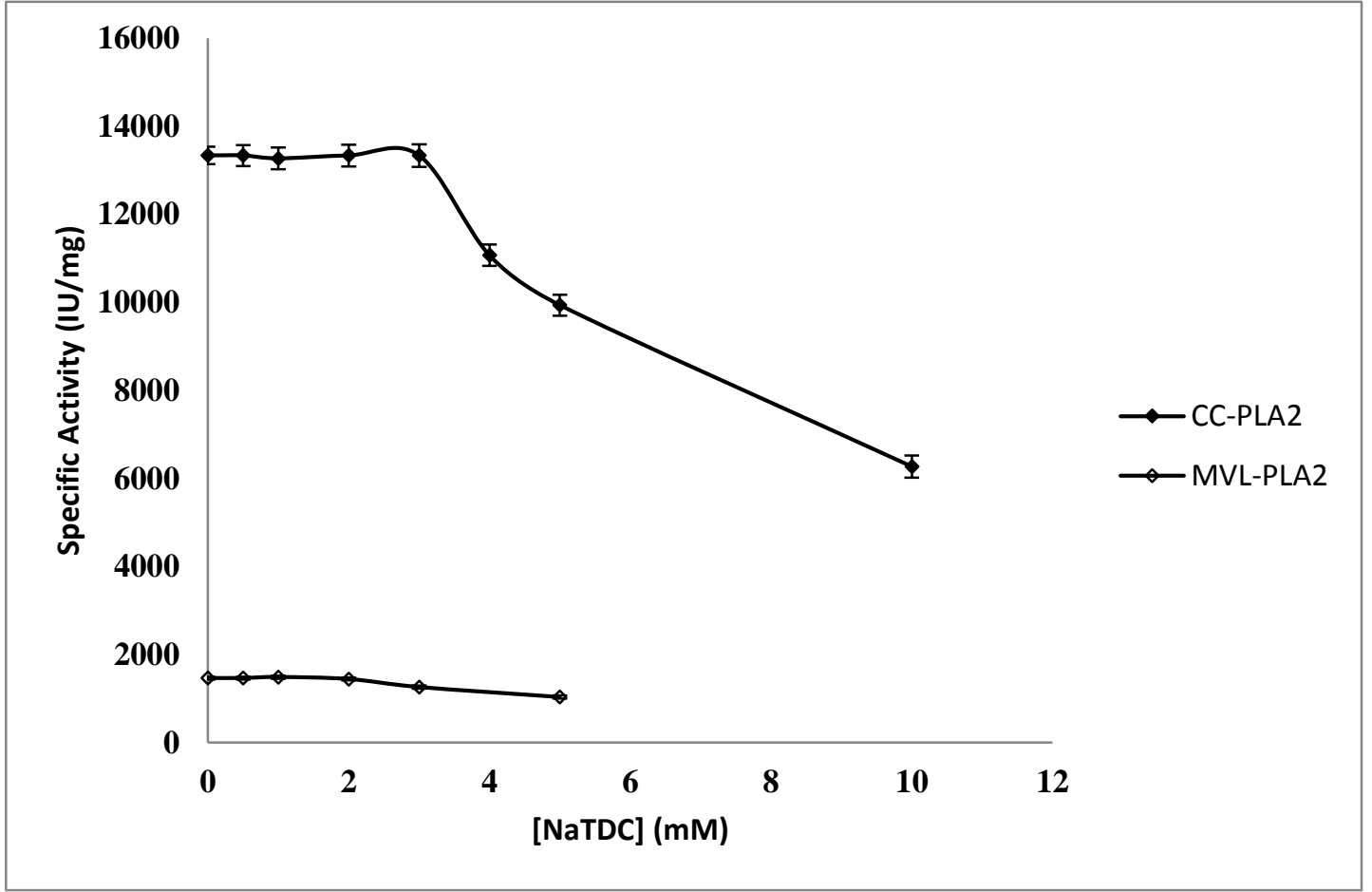


Fig.5.
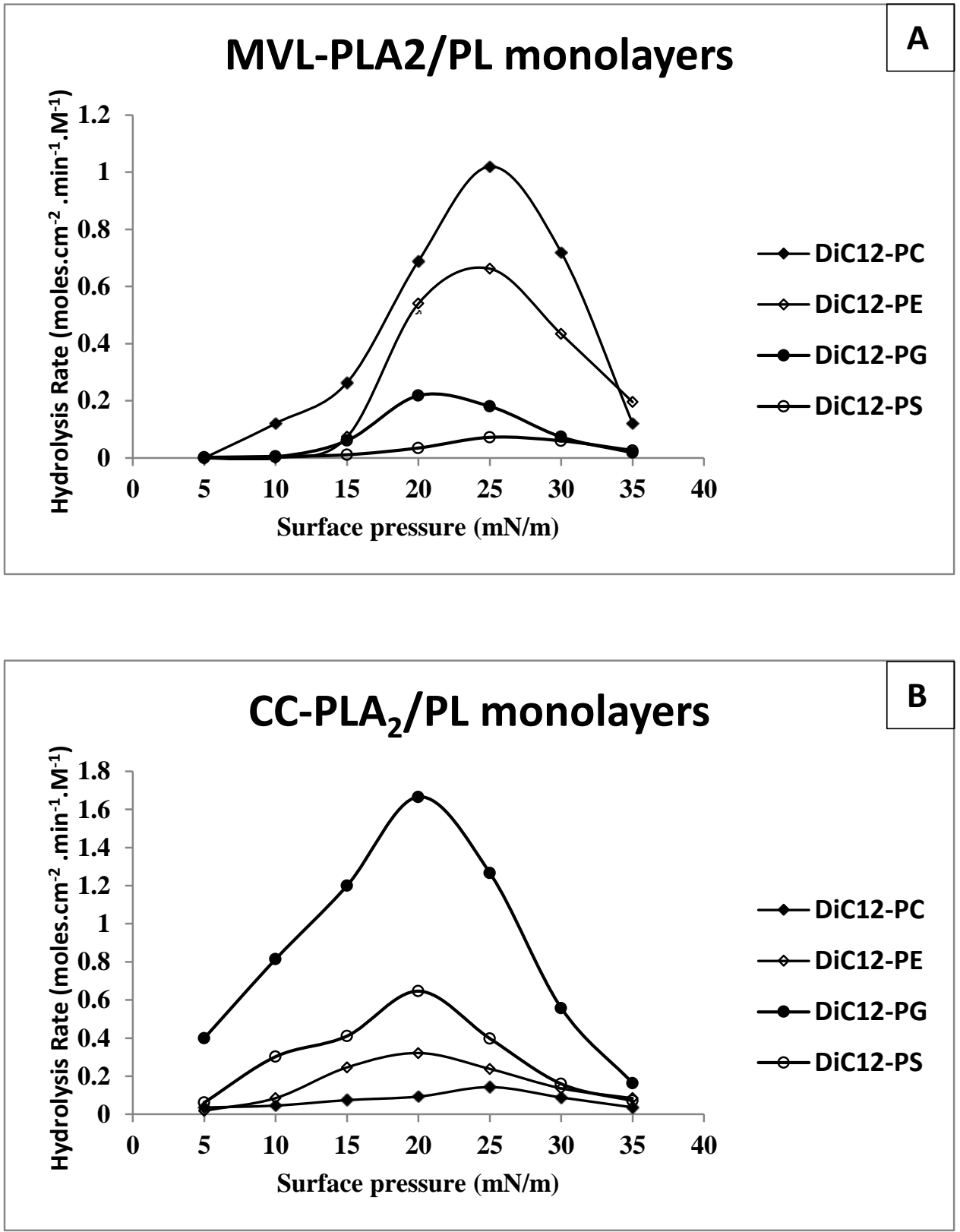
Fig.6.

CC-PLA2

MVL-PLA2

Vipoxin/1AOK

Myotoxin I//1GOD

BthA-I-PLA2/1ZL7

bAhp/1JIA

CC-PLA2

MVL-PLA2

Vipoxin/1AOK

Myotoxin II/1GOD

BthA-I-PLA2/1ZL

bAhp/1JIA
LFYSSSYCEEESEQC
MLYSLFDCMEESEK
KFLSSSRCRQTGEK
KIYPKPLCK - KADAC
WFYGAKNCQEKSEPC

NLYQFGKMIKHKTGKSALLSYSAYGCYCGWGGQGKPQDATDHCCFVHD ISY VYYCYCGLGGKKPQDATDRQ

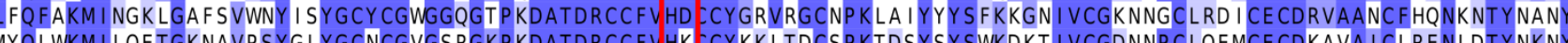
SMYQLWKMI LQETGKNAVPSYGLYGCNCGVGSRGKPKDATDRCCFVHK CCYKKLTDCSPKTDSYSY SWKDKTIVCGDNNPCLQEMCECDKAVA I CLRENLDTYNKNY

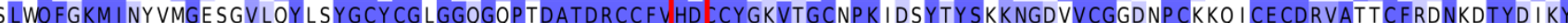
HLLQFRKMI KKMTGKEPVVSYAFYGCYCGSGGRGKP KDATDRCCFVHD CCYEKVTGCDPKWDDYTY SWKNGTIVCGGDDPCKKEVCE CDKAAA I CFRDNLKTYKKRY

Vipoxin/1AOK

$100.00 \quad 48.76 \quad 59.02$

53.28

56.20

59.84

Myotoxin II/1GOD

$100.00 \quad 49.59$

$61.16 \quad 47.50$

49.59

BthA-I-PLA2/1ZL7

100.00

$62.30 \quad 57.02 \quad 61.48$

$100.00 \quad 56.20 \quad 63.11$

CC-PLA2

$100.00 \quad 70.25$

MVL-PLA2

Fig.7.

PC

00000000000000000000000

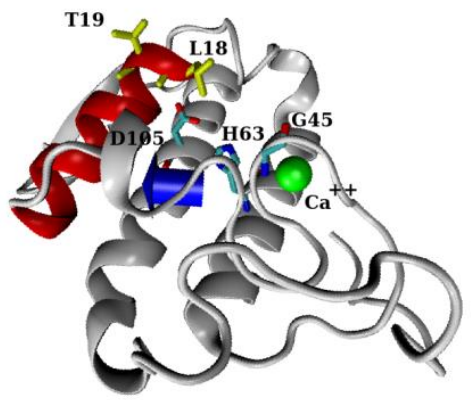

MVL-PLA2

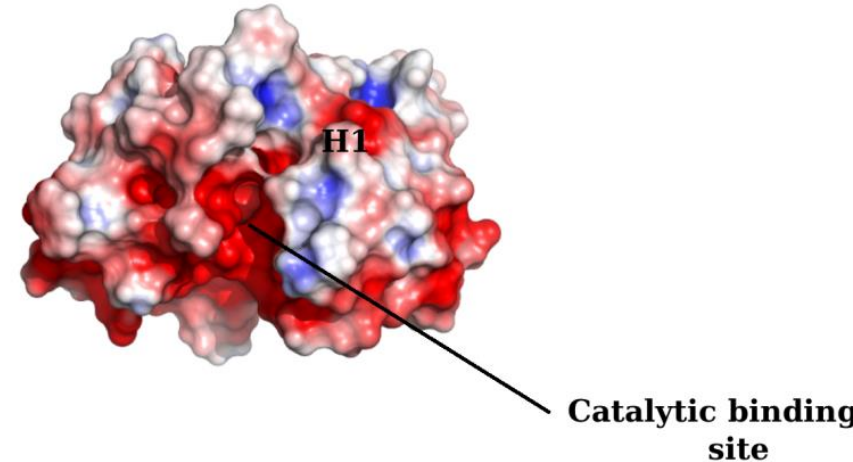

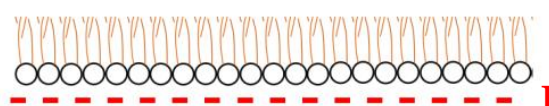

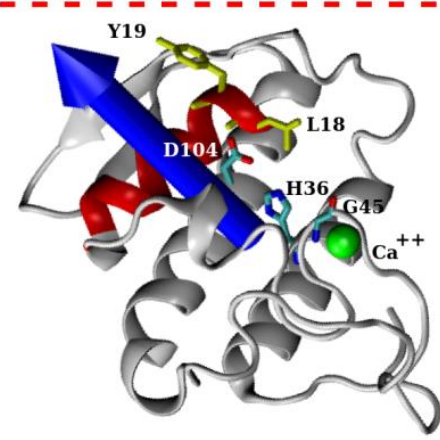

CC-PLA2

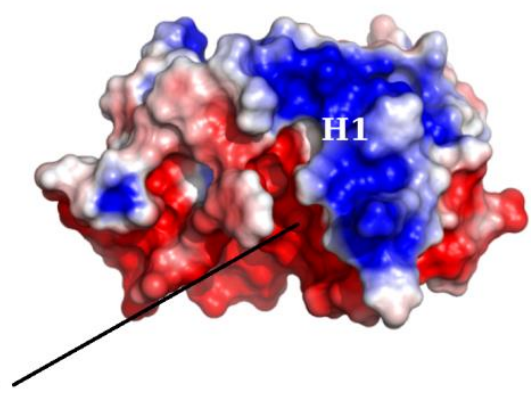


Table 1: Comparative properties between MVL-PLA2 and CC-PLA2.

\begin{tabular}{|l|l|l|l|l|}
\hline Name & \multicolumn{2}{l}{ MVL-PLA2 } & \multicolumn{2}{l|}{ CC-PLA2 } \\
\hline Activity $\left(\mathrm{Mol} \mathrm{cm}^{-2} \mathrm{~min}^{-1} \mathrm{M}^{-1}\right)$ & DiC12-PC & 1.019 & DiC12-PC & 0.143 \\
\hline & DiC12-PE & 0.662 & DiC12-PE & 0.320 \\
\hline & DiC12-PG & 0.218 & DiC12-PG & 1.665 \\
\hline & DiC12-PS & 0.072 & DiC12-PS & 0.646 \\
\hline Optimal Surface Pressure $(\mathrm{mN} / \mathrm{m})$ & & & & \\
\hline & DiC12-PC & 25 & DiC12-PC & 25 \\
\hline & DiC12-PE & 25 & DiC12-PE & 20 \\
\hline & DiC12-PG & 20 & DiC12-PG & 20 \\
\hline & DiC12-PS & 25 & DiC12-PS & 20 \\
\hline Isoelectric point $($ Ip $)$ & & & & \\
\hline Net surface charge & 4.49 & 4.92 & \\
\hline Ca ${ }^{2+}$ requirement & -16 & -16 & \\
\hline Optimal Temperature $\left({ }^{\circ} \mathrm{C}\right)$ & + & $\mathbf{+}$ & $\mathbf{6 0}^{\circ} \mathbf{C}$ & \\
\hline
\end{tabular}

